\title{
Workplace support and exclusive breastfeeding practice: a qualitative study in Jakarta, Indonesia
}

\author{
Yunita Febrianingtyas ${ }^{1,2}$, Judhiastuty Februhartanty ${ }^{2 *} \&$ Dian Nurcahyati \\ Hadihardjono ${ }^{3}$
}

${ }^{1}$ Nutrition Department, Faculty of Medicine, Universitas Indonesia, Central Jakarta, Indonesia; ${ }^{2}$ SEAMEO RECFON (Southeast Asian Ministers of Education Organization Regional Centre for Food and Nutrition)/Pusat Kajian Gizi Regional (PKGR)

Universitas Indonesia, Jakarta, Indonesia; ${ }^{3}$ Helen Keller International, Jakarta, Indonesia

\begin{abstract}
Introduction: The primary reason that compels working mothers to decrease their ability to continue to breastfeeding successfully is their return to work. Attempts to continue breastfeeding at work encounters several difficulties. This study aims to provide an overview of the workplace environment and how facilities at the workplace affect breastfeeding in Indonesia. Methods: We used a qualitative approach to provide a detailed picture of the influence of workplace support for working mothers to perform breastfeeding. We enrolled working mothers $(n=18)$ in Jakarta, as participants and obtained the following information from them: parity, type of family and type of work. Results: The findings provided the general overview of the workplace environment and identified three factors that affected breastfeeding: seeking information during pregnancy, expression of breast milk at office facilities and the problem faced by working mothers. Conclusion: Although the breastfeeding performance of most working mothers in this study comprised exclusive breastfeeding, some fed their infants with formula milk. This study suggests that working mothers who continue to breastfeed after returning to work need the support of their employers, co-workers and others in the workplace to ensure the provision of health facilities and the protection and dissemination the rights of breastfeeding working mothers that might lead them to discontinue their breastfeeding practice.
\end{abstract}

Keywords: Breastfeeding performance, workplace support, qualitative study, Jakarta, Indonesia

\section{INTRODUCTION}

For the first 6 months of life, breast milk alone is the optimal way to feed infants as it provides all the necessary nutrients for growth, and protection by way of antibodies from the mother (UNICEF, 2011). In addition, exclusive breastfeeding (EBF) is the most effective preventive intervention to improve children's health and survival (Black et al., 2008; Kramer et al., 2003). Several studies have established the benefits of breastfeeding for mothers. Prolonged breastfeeding might may also provide protection from ovarian cancer, rheumatoid arthritis, endometrial cancers, osteoporosis in the future and also help mothers regain normal 
weight quicker (500-640 calories loss whilst breastfeeding); it provides economic benefit for the family because breastfeeding does not cost anything (Rea, 2004; Wen et al., 2009).

In developing countries, the prevalence of breastfeeding for $<6$ months is only $37 \%$. There has been with little progress in the breastfeeding rate since the early 1990s (UNICEF, 2011). The Indonesia Demographic and Health Survey (2012) revealed that only $27 \%$ of infants aged $4-5$ months received exclusive breastfeeding in Indonesia (Statistics Indonesia et al., 2013). Statistics Indonesia (2008) revealed that the prevalence of working women in the Special Capital Region (Daerah Khusus Ibukota, DKI) Jakarta was 56.71\%. Recently, Basrowi et al. (2015) reported that proportion of working mothers in Jakarta who exclusively breastfed their children was only $32.2 \%$.

Ong et al. (2005) reported that the primary obstacles amongst working mothers were because of the breast milk supply. Working mothers encounter several challenges to breastfeeding such as the lack of knowledge about breastfeeding practices, insufficiency of time needed to breastfeed or express breast milk, short maternity leave, breastfeeding problems during the first 6-month period, the lack of breastfeeding facilities and programmes at workplaces, management of expressed breast milk and the impact of media about formula feeding (Ryan, Zhou \& Arensberg, 2006; Basrowi et al., 2015; Fauzie et al., 2007; Manjilala, 2012; Marinelli et al., 2013). Another study reported that a breastfeeding plan could help working mothers anticipate the pumping schedule by considering where and how frequently breast pumping could be performed, break schedule and work hours, and barriers they encounter in their workplaces (Biagioli, 2003). Likewise, some working mothers stated not preparing breast milk stocks during the maternity leave because of the lack of knowledge and delay in saving breast milk adversely affected their breastfeeding performance. A qualitative study in Lebanon reported that preparing future mothers for successful breastfeeding later in life might augment their determination and self-confidence to overcome breastfeeding problems (Nabulsi, 2011).

The role of workplace support for working mothers as a vital factor that could affect breastfeeding frequency has scarcely been investigated in Indonesia, especially Jakarta. A qualitative approach was deemed the most appropriate way to explore the understanding of mother's experiences related the workplace environment and facilities to support their exclusive breastfeeding practice. A qualitative approach is focused on the experiences, knowledge and understanding of a given issue, meanings, and explanations and rationale given by people to justify their decisions and actions of some behaviour (Kielmann, Cataldo \& Seeley, 2012).

\section{MATERIALS AND METHODS}

\section{Study design and participants}

This qualitative study used the grounded theory approach which is an iterative process, requiring a steady movement between concept and data. The data is then consolidated and analysed to produce the theory (Lawrence \& Tar, 2013). We enrolled working mothers aged 24-45 years in this study. The inclusion criteria comprised white-collar workers (government/private/United Nations, UN/Non-Governmental Organisation, NGO) with full-time working status (8-12 h/day), working mothers who had returned to work after maternity leave, had a child aged $<6$ months and who were willing to participate. Whitecollar workers were chosen because the facilities and the time of working status usually were similar in each workplace. A study in Taiwan mentioned that the 
white-collar working mothers had more control over their environment and schedules than blue-collar working mothers (Tsai, 2013). The exclusion criteria comprised mothers who lived separately from their child. In order to obtain data from a variety of participants, the following features were used to select them, namely, parity, type of family, and type of work. These characteristics considered the factors that influenced the result of in-depth interviews among working mothers (Table 1).

Twenty-four offices in Jakarta (government/private/UN/NGO) were randomly selected for this study. Letters requesting permission to interview some of their employees were sent to them. Only 14 offices gave permission to
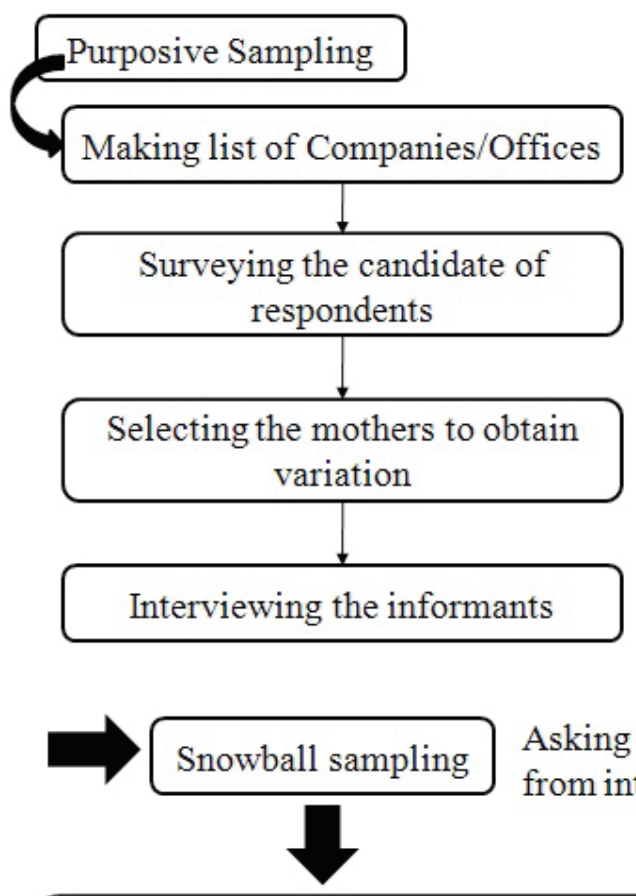

Asking for another possible informants from interviewed informants'

\section{The Informants: \\ 18 working mothers}

7 government employers, 8 private employers, 3 UN/NGO employers

Figure 1. Sampling procedure of the study
Table 1. Type of working mothers in this study and sample size (total $n=18$ )

\begin{tabular}{lc}
\hline Type & $n$ \\
\hline Parity & 9 \\
Primiparous & 9 \\
Multiparous & \\
Type of family & 6 \\
Nuclear family & 12 \\
Extended family & \\
Type of work & 7 \\
Government & 8 \\
Private & 3 \\
UN/NGO & \\
\hline
\end{tabular}

conduct the interviews. The participants were recruited by the contact person within the organisation who selected the working mothers who had fulfilled the inclusion criteria, ensuring that there

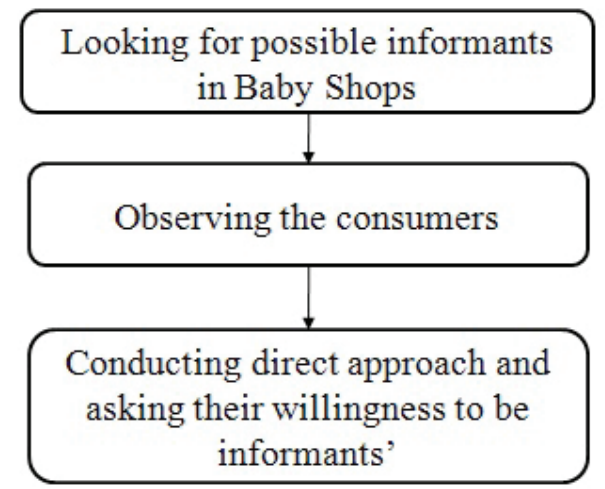


was adequate variation of data based on parity, type of family, and type of work could be obtained. The participants comprised 18 working mothers to reach theoretical saturation. Theoretical saturation is the point when additional data collected from other participants is going to develop or add to the concepts that have been drawn from the previous interviews (Lawrence \& Tar, 2013). The snowball sampling technique was used as it enables previous participants to recommend potential participants to obtain the study variation (Marshall, 1996). The flow of the study sampling procedure is described in Figure 1.

\section{Data collection}

We conducted the interviews in offices, canteens, restaurants, lactation rooms and meeting rooms. In the first meeting, interviews were conducted hastily because of the limited time that was available during office hours. However, some participants provided additional insights either through second visits or telephone calls. The questions served as a guide to those that would be asked and covered topics such as their current exclusive breastfeeding practices; the workplaces environment factors that affected exclusive breastfeeding; and the experiences of working mothers that were related to breastfeeding practices such as previous success and failure experiences and observation of others encouraging or discouraging messages from others, and emotional issues related to breastfeeding. Eighteen mothers completed the interviews. The small number of participants was deemed sufficient as they had adequately responded to the research questions (Marshall,1996). Also a similar number was used in a previous qualitative study by interviews of 17 mothers of their experiences, the challenges they faced and the coping mechanism to overcome those challenges (Wilson et al., 2012).
To validate our findings, we undertook conducted triangulation which is the process of verification to increase the validity of information from in-depth interview results and it offered a comprehensive picture by combining several perspectives and approaches (Yeasmin \& Rahman, 2012). This was done through four interviews with key participants (managers, breastfeeding counsellors and co-workers) and five observations of lactation room in workplaces. In this study, the instruments used were $24-\mathrm{h}$ recall (to estimate exclusive breastfeeding amongst mothers by asking about the feeding practice for the day, $24 \mathrm{~h}$ before the interview), in-depth interviews and guidelines for investigating workplace facilities for the practice of breastfeeding/ breast-milk expression amongst working mothers. The areas covered by triangulation comprised workplace facilities and the environment that affected breastfeeding at the workplace.

\section{Data analysis}

At the end of each interview a de-briefing was undertaken to consolidate and analyse in-depth the data, to ensure the questions guide were relevant. The questions were pre-tested in different places which had the same characteristics as the study area. In the pre-testing phase, three working mothers were interviewed. Data from the pre-testing ascertained the flow of the interview, the suitable topics of conversation that could be used for interviews of working mothers to build rapport. If there were any difficulties in understanding the terms used in the guidelines, appropriate revisions were made to it. The characteristics of the interviewees were assessed in the beginning of the interview. The primary steps of data analysis in this qualitative study were transcribing, coding, analysis and data display. Firstly, a trained transcriber transcribed verbatim the interview recordings and all crucial points 
relevant to the research question were underlined. Secondly, data were coded. Coding is an interpretive technique to organise the data. After transcripts were coded they were checked for consistency to ensure that researchers used coding consistently in the same text individually (Kielmann et al., 2012). Then, codes were grouped into themes to decrease the number of categories. Finally, the results of interviews were presented in the form of themes and quotations to support the pattern identified in this study.

\section{Ethics}

This study protocol was approved by the Ethical Committee of Medical Faculty of University of Indonesia (Jakarta,
Indonesia; number 124/H2.F1/ ETIK/2014). Permission from local governments (provincal, district and subdistrict level) and local authorities was obtained before the data collection. We obtained written informed consent from all informants prior to data collection.

\section{RESULTS}

\section{Characteristics of the study participants}

The mothers in this study had a high level of education with 14 of the 18 having either postgraduate or first degrees. Most of them (11 out of 18) worked in the private sector or NGOs/ UN. The family income of mothers

Table 2. Characteristics of study participants $(n=18)$

\begin{tabular}{lc}
\hline Characteristics & $n(\%)$ \\
\hline Age (years) & \\
$21-30$ & $10(55.6 \%)$ \\
$31-40$ & $8(44.4 \%)$ \\
Level of Education & \\
Post-graduate degree & $4(22.2 \%)$ \\
Bachelor's degree & $13(72.2 \%)$ \\
Diploma & $1(5.6 \%)$ \\
Type of Employer & \\
Government & $7(38.9 \%)$ \\
Private & $8(44.4 \%)$ \\
UN/NGO & $3(16.7 \%)$ \\
Family Income (per month) & \\
<2,400,000 IDR (<165.76 USD) & $1(5.6 \%)$ \\
2,400,000-6,000,000 IDR (165.76 - 414.39 USD) & $2(11.1 \%)$ \\
6,000,000-10,000,000 IDR (414.39 - 690.65 USD) & $5(27.8 \%)$ \\
>10,000,000 IDR (>690.65 USD) & $9(50 \%)$ \\
Ethnicity & \\
Javanese & $8(44.4 \%)$ \\
Padangese & $2(11.1 \%)$ \\
Betawi & $5(27.8 \%)$ \\
Sundanese & $1(5.6 \%)$ \\
Bataknese & $1(5.6 \%)$ \\
Manado & $1(5.6 \%)$ \\
Parity & \\
Primiparous & \\
Multiparous & $9(50.0 \%)$ \\
Type of Family & $9(50.0 \%)$ \\
Nuclear family & \\
Extended family & $6(33.3 \%)$ \\
\hline
\end{tabular}


was mostly >6,000,000 IDR (414.39 USD) and most of the mothers were of Javanese ethnicity. The numbers of primiparous and multiparous was equal and all multiparous mothers had two children. Two-thirds of the mothers lived in extended families (Table 2).

\section{Workplace environment}

The lack of internal regulations that support breast-milk expression

Some mothers mentioned that their workplaces had no facilities for breastmilk expression that were provided by the management. However, those who worked in the civil service and the UN/ NGOs had a better chance of being permitted to undertake breast-milk expression by the superior than those working in a private company.

The following are excerpts of some comments of the mothers on breastfeeding:

Expression of breast-milk at the workplace Often, seeking permission to express breast milk made many participants uncomfortable:

'I felt uncomfortable to express breast milk at office hours, because if I had a meeting and it coincided with my pumping schedule, I could not ask permission from my supervisor. Therefore, I delayed my pumping schedule until after the meeting ends' (A mother who partially breastfed and worked in the private sector).

However, some managers permitted mothers to express their breast milk during work hours:

'Until now there are no internal regulations to support exclusive breastfeeding programme in our office. However, if any of our staff want to express the breast milk, we are very supportive for that' (A manager of the UN/NGO sector).

'There are no pressures from the superior, so I have to adjust my time and work efficiently' (A mother who exclusively breastfed and worked in the government sector).

Maternity leave of less than 6 months Every working mother would wish for a 6-month maternity leave so as to focus on breastfeeding their infant exclusively for whole 6 months. However, a mother who received maternity leave of $>3$ months thought that maternity leave was highly useful:

'Maternity leave is very important to me and my baby... I got the maternity leave for four months: 1 month before delivery and 3 months after delivery. I'm so glad because I have so much time with my baby' (A mother who exclusively breastfed and worked in the UN/NGO sector).

Some mothers, who only had 3 months of maternity leave, wanted 6 months for exclusive breastfeeding:

'Actually I wanted to have maternity leave for 6 months so (that) I can give exclusive breastfeeding and (be) at home with the child, but it seems impossible' (A mother working in the government sector).

Although mothers did not get 6 months of maternity leave, at least, the availability of a lactation room would allow working mothers to express their breast milk for their child. Given below is the response from a breastfeeding counsellor:

'Although the government cannot set the policy on maternity leave for 6 months, the availability of a lactation room in the office will allow working mothers to give the expressed breast milk to her child' (A breastfeeding counsellor who gives counselling in the lactation room).

\section{Support from co-workers}

Most respondents received support from colleagues who had previously breastfed. Support from co-workers mattered for some mothers because, during working time, they always met with them while expressing breast milk:

'I have a co-worker that always cheer 
me up with expressing the breast milk. Sometimes I feel so bored with the same breast pumping activity but she said that even though my baby have nipple confusion, I can still have the bonding between me and my daughter... It encouraged me to keep giving breast milk through expressed breast milk' (A mother who worked in the private sector).

A co-worker shared her experience that makes her suggestion was accepted with her friends:

'I always try not to judge the mothers, because no mother wants to be judged. Therefore, during pumping together in the lactation room, I often tell stories about my breastfeeding experiences and send an article about breastfeeding and related matters' (A mother who worked in the private sector and always encouraged her friends in the office to continue breastfeeding).

The perceptions of co-workers about breastfeeding

The perception of co-workers that breastmilk is the best food for children is quite widespread. Some mothers mentioned that their co-workers often discussed breastfeeding practice:

'I think in this office breastfeeding practice is quite popular. Sometimes when we have a discussion, there are mothers who feel sad because they are not exclusively breastfeeding' (A mother who worked in the government sector).

However, a mother revealed a different perception of her co-workers about breastfeeding:

'My perception is that breastfeeding is not popular in my office. My co-workers do not seem to know the importance of breastfeeding. For instance, when my friend was not permitted to wash her breast pump equipment in the pantry because other co-workers felt disgusted. So, I didn't use the pantry anymore' (A mother who worked in the private sector).

\section{Seeking information during pregnancy}

Table 3 shows that working mothers who exclusively breastfed their child were more likely to seek information about infant-feeding during pregnancy rather than predominant and partial breastfeeding working mothers.

\section{Expressing breast milk at workplace facilities}

Experiences

In offices, the most frequent place used to express breast milk was the lactation room. However, mothers faced many challenges, such as the inappropriateness of lactation room, its distant location, and the lack of facilities that support mothers to express breast milk. The following are some comments that were made by breastfeeding mothers:

'My office already provides a lactation room, but the location was poorly suited. It is located in front of male ablution room, therefore I do not want to express breast milk there... Besides the air is so humid and musty...' (A mother who worked in the government sector and who exclusively breastfed).

A different reason shared by others about the lactation room:

'Actually there is lactation room on the 22nd floor but it's too far from my room. Just for time efficiency, I have to express my breast milk in the toilet...' (A mother who worked in the private sector and who exclusively breastfed). Some mothers who did not have a lactation room in their office expressed breast milk in an available room, meeting room, and classroom:

'Although there is no lactation room in my office, I can still express my breast milk in the unused room. I should be grateful... as previously, I used the toilet for expressing my breast milk' (A mother who worked in the government sector who expressed her breast milk in the unused room). 
In this study, we conducted some of the interviews in a lactation room. Figure 2 illustrates the various lactation rooms found in each workplace. Every workplace had different standards and facilities to support the breast-milk expression practice for working mothers. Some workplaces offered full facilities to support working mothers to express their breast milk but some provided fewer, as a result of which the mothers felt less comfortable.

Limited time to expressed breast milk Some mothers reported the problem of managing their break time for lunch, pray and expression of breast milk. Those who worked in government and UN/NGO sectors had a greater flexibility of time compared with those who worked

Table 3. Methods of obtaining information about breastfeeding during pregnancy according to type of work place

\begin{tabular}{|c|c|c|c|}
\hline \multirow{2}{*}{$\begin{array}{l}\text { Source of } \\
\text { information }\end{array}$} & \multicolumn{3}{|c|}{ Type of work place } \\
\hline & Government sector & Private sector & $U N / N G O$ \\
\hline $\begin{array}{l}\text { During } \\
\text { pregnancy }\end{array}$ & $\begin{array}{l}\text { Seeking information about } \\
\text { breastfeeding via the } \\
\text { internet and then sharing it } \\
\text { with other co-workers } \\
\text { - Getting information from } \\
\text { reading articles, internet, } \\
\text { or sharing information } \\
\text { with people who have been } \\
\text { breastfeeding before (EBF) } \\
\text { - Reading books on childcare } \\
\text { and from internet search } \\
\text { (EBF) }\end{array}$ & $\begin{array}{l}\text { Joining } \\
\text { breastfeeding class } \\
\text { (EBF) } \\
\text { Getting information } \\
\text { from high school } \\
\text { friends or family } \\
\text { experience (EBF) } \\
\text { Joining a seminar } \\
\text { provided by the } \\
\text { company about } \\
\text { breastfeeding (EBF) } \\
\text { Sharing with co- } \\
\text { workers (EBF) }\end{array}$ & $\begin{array}{l}\text { - Seeking } \\
\text { information } \\
\text { about } \\
\text { breastfeeding } \\
\text { via the internet } \\
\text { and sharing } \\
\text { information } \\
\text { from family } \\
\text { experience } \\
\text { (EBF) } \\
\text { Reading } \\
\text { books, sharing } \\
\text { information }\end{array}$ \\
\hline $\begin{array}{l}\text { After } \\
\text { childbirth }\end{array}$ & $\begin{array}{l}\text { - After childbirth, much } \\
\text { information can be obtained } \\
\text { from the husband or the } \\
\text { obstetrics \& gynaecology } \\
\text { specialist (predominant BF) } \\
\text { - Getting information } \\
\text { about breastfeeding via } \\
\text { the internet and asking a } \\
\text { counsellor at the lactation } \\
\text { room (EBF) } \\
\text { - Getting information about } \\
\text { breast milk only from the } \\
\text { TV shows (similar to talk } \\
\text { shows) (an infant getting a } \\
\text { breast milk donor because } \\
\text { the mother had baby blues) } \\
\text { Getting information only } \\
\text { from the husband (EBF) }\end{array}$ & $\begin{array}{l}\text { - Getting information } \\
\text { from the obstetrics } \\
\text { \& gynaecology } \\
\text { specialist after } \\
\text { childbirth (EBF) } \\
\text { - Looking for } \\
\text { information on the } \\
\text { internet after having } \\
\text { a breastfeeding } \\
\text { problem (e-Ping) } \\
\text { - Reading the } \\
\text { magazine on } \\
\text { childcare or } \\
\text { parenting (partial } \\
\text { BF) }\end{array}$ & $\begin{array}{l}\text { with co-workers } \\
\text { and joining } \\
\text { breastfeeding } \\
\text { class } \\
\text { Attending } \\
\text { training } \\
\text { about how } \\
\text { to breastfeed } \\
\text { correctly (partial } \\
\text { BF due to HIV+) }\end{array}$ \\
\hline
\end{tabular}

Note:

$\mathrm{EBF}=$ exclusive breastfeeding

$\mathrm{BF}=$ breastfeeding

HIV+ = HIV positive

e-Ping = exclusively pumping (means meeting all the infant's milk needs through expressing breastmilk only) 


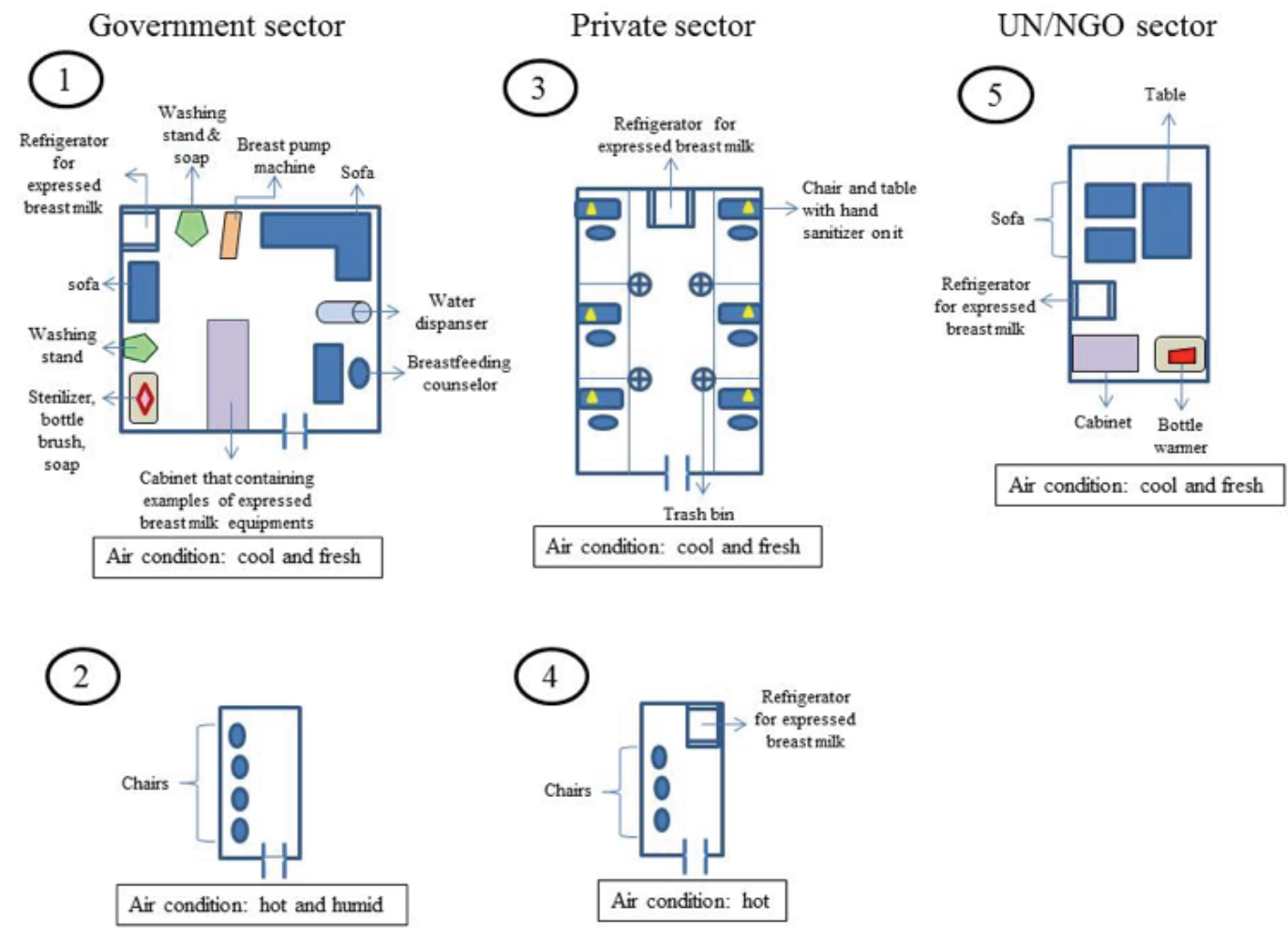

Figure 2. Arrangements and setting of some observed lactation rooms

in private sector as the latter group had rigid work hours and shorter break times. Some even reported that they had to add working hours to replace the break they used for breast-milk expression:

'Essentially, I had to work eight hours a day, every time I took the break it means I had to replace it whatever the time I used' (A mother who exclusively breastfed and worked in the private sector).

Some mothers reported going to offices earlier than office hours for expressing their breast milk:

'Sometimes expressing breast milk was really time-consuming, so I go early in the morning so as to express my breast milk first. During lunch break, I expressed my breast milk using breast pump for the right side and my hand for the left side. I think that's really good strategy to save my time' (A mother working in the private sector who exclusively breastfed).

\section{Breastfeeding problems}

Table 4 indicates the several problems faced by working mothers who returned to work. Primarily, working mothers experienced difficulty in expressing breast milk during working hours and managing breast milk stocks. Some other challenges were inadequate knowledge and breastfeeding experience and its related matters such as when babies had nipple confusion because of being fed by bottles, mothers' illness, and inappropriate lactation room in offices.

\section{DISCUSSION}

\section{Breastfeeding practice of working mothers}

In this study, working mothers revealed that the chief obstacles they faced during 
Table 4. Problems faced by working mothers who returned to work

\begin{tabular}{ll}
\hline Problems faced by working mothers & \multicolumn{1}{c}{ Elaboration } \\
\hline $\begin{array}{l}\text { Unprepared breast milk stocks during } \\
\text { maternity leave }\end{array}$ & $\begin{array}{l}\text { Inadequate knowledge and experience } \\
\text { about expressed breast milk }\end{array}$ \\
\hline $\begin{array}{l}\text { Difficult to express breast milk during } \\
\text { working hours }\end{array}$ & $\begin{array}{l}\text { Delay to save breast milk } \\
\text { - } \begin{array}{l}\text { Hecreased frequency due to work-load } \\
\text { time }\end{array} \\
\text { - Having difficulties to ask permission }\end{array}$ \\
\hline Nipple confusion (e-Ping $\left.{ }^{\dagger}\right)$ & - Prolonged bottle use for expressed breast \\
& milk \\
\hline $\begin{array}{l}\text { Mothers' illness influenced breast milk } \\
\text { production }\end{array}$ & Adaptation after maternity leave \\
\hline Inappropriate lactation room & - The location is too far from her desk \\
& - Lack of facilities \\
& The room temperature is too hot \\
\hline
\end{tabular}

${ }^{\dagger}$-Ping = exclusively pumping (means meeting all the infant's milk needs through expressing breastmilk only)

their breastfeeding practice were the difficulty in finding places to express their breast milk during working hours and managing the breast milk stocks because of low milk supply. Some of them revealed that upon returning to work, their breastfeeding performance was reduced, accounting for sickness in some, because of the need to adapt their breastfeeding/ breast-milk expression to the home and office. A study on comprehending the maternal breastfeeding confidence revealed that returning to work could challenge mothers' ability to breastfeed successfully if they perceive that they will be able to express adequately to meet their infant's needs. This suggest that health care professionals should discuss with mothers about their plans for breastfeeding and to be prepared upon returning to work (Grassley \& Nelms, 2008). Mothers started using expressed breast milk, not only after their return to work but also during the maternity leave to compensate for the times they were tired. This caused another problem of nipple confusion among babies after being introduced to bottles too early in life. The finding was confirmed by Biagioli (2003) who reported that introducing a bottle too early (at the age of $<1$ month) could cause nipple confusion because feeding on a bottle required less suction and less coordination of tongue movements and resulting in babies rejecting nipples when breastfed.

\section{Workplace environment}

Returning to work after maternity leave is a vital factor possibly affecting breastfeeding practice amongst working mothers. Most studies reported that breastfeeding working mothers expressed their breast milk regularly, stored it, and brought home after work. However, working mothers reported encountering several problems such as inappropriate lactation rooms, distance location of the lactation room, lack of facilities, limited time to express breast milk and the lack of formal support for breast-milk expression by the management. Every workplace had different facilities that served as lactation rooms and some were observed to be inappropriate.

These findings were not consistent with the Ministry of Health's circular (No. 872/Menkes/XI/2006) about 
the criteria and facilities for lactation rooms. The Government Regulation on Breastfeeding No. 33 in 2012 about the Exclusive Breastfeeding Practice, Indonesia, stated that every workplace and public facility should support exclusive breastfeeding programmes by providing appropriate facilities and rooms for mothers to express their breast milk (Article 30-Workplace and Public Facilities). In addition, regulations about time and internal regulations are mentioned in Article 34 and 35-every management or executive board of a workplace should provide opportunities for working mothers to breastfeed or express their breast milk during working hours and introduce internal regulations supporting successful exclusive breastfeeding programmes (Ministry of Health, 2012).

Although many offices do not have internal regulations to support exclusive breastfeeding programmes, several supervisors permitted their staff if they wanted to express their breast milk during work hours. The support of coworkers influenced the breastfeeding practices amongst working mothers; some mothers revealed that support from co-workers was significant to increase their motivation. These findings are supported by many studies which report that working mothers who continued their breastfeeding after returning to work needed the support of their employers, co-workers and other people in the workplace to ensure the provision of lactation room and facilities. Protecting and disseminating information, on the rights of breastfeeding working mothers, may encourage them to continue their breastfeeding practice (Basrowi et al., 2015; Hirani \& Karmaliani, 2013; Kolinsky, 2010; Shealy et al., 2005).

Based on interviews, most working mothers in the government sector had more time to express their breast milk than their counterparts who worked elsewhere. This finding corroborated a cross-sectional study in Malaysia, which reported that working mothers in government sectors were more likely to have flexible time to express their breast milk compared with those working in private sector because the private sector had stricter rules and shorter breaks (Amin et al., 2011).

The duration of maternity leave was another vital factor for working mothers. In this study, working mothers revealed that they only had 3 months of maternity leave. Typically, they took 1 month before delivery and 3 months post-delivery. Most felt that a 6-month maternity leave could enable them to exclusively breastfeed their infants for 6 months. A qualitative study in Pakistan reported that working mothers were worried and stressed because they always thought about their infant during working hours (Zafar \& Bustamante-Gavino, 2008). The government's perspective in this study was that it already released rules and regulations on breastfeeding in workplaces to assist working mothers in continuing the breastfeeding practice by expressing their breast milk. However, the facilities and conveniences provided by most workplaces were still lacking. A study in one Indonesian company by Lestari, Trisyani \& Widiasih (2014) reported that the regulation, Law no. 13 of 2003, concerning the employment in Indonesia, offered the maternity leave for only 1.5 months; this period was not consistent with the recommendations by the International Labour Office (ILO), which recommended, at least, an 18week maternity leave (ILO, 2010). Thus, the maternity leave implemented by the Indonesian government was still less than that recommended by the ILO. Another study concluded that strong management support at workplaces and relevant policies of employers played avital role in providing supportive workplace environments, appropriate facilities, to make working mothers feel adequately supported and encouraged to continue breastfeeding upon returning to work (Weber et al., 2011). Yet another study 
reported that post-partum maternity leave might exert a positive impact on breastfeeding amongst full-time working mothers. In this study, short postpartum maternity leave amongst fulltime working mothers correlated with a higher risk of early discontinuation of breastfeeding (Guendelman et al., 2009). Flacking, Dykes \& Ewald (2010) reported that paternity leave might help mothers to breastfeed up to 6 months.

The duration of maternity leave in Indonesia as mentioned in Government Regulation No. 241976 paragraph 19 , states that women can remain absent 1 month before and 2 months post-delivery (Ministry of Health, 2008). However, a discrepancy exists between the government practices and its health programmes which calls for the implementation of exclusive breastfeeding for up to 6 months. To implement that programme, all working mothers should receive the 6 months of maternity leave to able them to practise exclusive breastfeeding.

\section{Seeking information during pregnancy}

This study suggests that one of the favourable points experienced by mothers who were exclusively breastfeeding as against those who were predominantly and partially breastfeeding was their desire to seek 'information during pregnancy about breastfeeding' (Table 3 ). The timing of exposure to information affected the ability of mothers to breastfeed successfully. Exclusively breastfeeding mothers tended to seek the information before having breastfeeding problems. Some mothers who received the information during pregnancy and right after delivery had some advantages to prepare for their breastfeeding practice. However, some mothers received the information only after developing breastfeeding problems. These findings were consistent with a study in Depok,
Indonesia, which concluded that earlier the mothers received good knowledge about breastfeeding, the better the level of confidence they exhibited in their practise (Februhartanty et al., 2012). Besides, the most accessed source of information amongst working mothers was the Internet because it was easily accessible and saved their time. A study in Malaysia reported that in most urban societies, mothers gathered the breastfeeding information from the Internet, demonstrating that the mass media could effectively disseminate the breastfeeding information as public education (Eeng et al., 2008). Thus, early appropriate support and information about breastfeeding and related matters during the reproductive age are imperative for mothers to prepare their breastfeeding practices.

\section{Breastfeeding problems}

In this study, mothers shared their feelings about their breastfeeding problems. For instance, mothers worried about their breast milk stock right after returning to work, and that made them lose confidence with their ability to breastfeed well; this result was supported by a prior study (Grassley \& Nelms, 2008). Thus, by decreasing emotional responses could increase the coping mechanism to tackle breastfeeding problems. A study in Depok, Indonesia reported that the support of fathers enhanced the decision to sustain breastfeeding (Februhartanty et al., 2012). This finding was also supported by a study in Canada by Rempel and Rempel (2011), who stated that expressions of support by fathers played a vital role in the positive responses of mothers towards breastfeeding. Fathers who extended emotional support, such as appreciating the breastfeeding practice of mothers, could reduce the emotional stresses faced by mothers (Rempel \& Rempel, 2011). 


\section{CONCLUSION}

Most working mothers practised exclusive breastfeeding, but some mothers performed mixed-feeding. Working mothers who continued breastfeeding after returning to work need the support from their employers and co-workers in the workplace, to maintain their confidence to continue breastfeeding. Ensuring the provision of necessary facilities, protecting and disseminating the rights of breastfeeding for working mothers were also important for this to happen. Continuous efforts are warranted to advocate the importance of improving the maternity leave to increase the practice of exclusive breastfeeding amongst working mothers. One limitation in this study was the absence of mothers who worked in factories, who may have different experiences from office workers in relation to breast-milk expression performance in the workplace.

\section{Acknowledgements}

The authors would like to acknowledge Airin Roshita, PhD for her expertise on how to conduct a qualitative research; Lina Handayani, $\mathrm{PhD}$ on the breastfeeding self-efficacy tools; Nia Umar, MKM, IBCLC on the context (point of view) of working mothers in Jakarta; and Lintang Purwara Dewanti, M. Gizi and Kiswatul Hidayah S. Gz for their support in data analysis; and all the participants for their willingness to participate.

\section{Authors' contributions}

YF, designed the research, conducted the data collection, data analysis and interpretation, and wrote the first draft of the manuscript; JF, designed the research, interpreted the data and gave substantial contribution to the final manuscript; $\mathrm{DNH}$, designed the research, interpreted the data and gave substantial contribution to the final manuscript.

\section{Conflict of interest}

The authors declare that they have no conflicts of interest.

\section{References}

Amin RM, Said ZM, Sutan R, Shah SA, Darus A \& Shamsuddin K (2011). Work related determinants of breastfeeding discontinuation among employed mothers in Malaysia. Int Breastfeed $J$ 6(4):1-6. https://doi. org/10.1186/1746-4358-6-4.
Basrowi RW, Sulistomo AB, Adi NP \& Vandenplas Y (2015). Benefits of a dedicated breastfeeding facility and support program for exclusive breastfeeding among workers in Indonesia. Pediatr Gastroenterol Hepatol Nutr. 18(2):94-99. https:/ / doi.org/10.5223/pghn.2015.18.2.94.

Biagioli F (2003). Returning to work while breastfeeding. Am Fam Physician 68(11): 2201$2208+2215$.

Black RE, Allen LH, Bhutta ZA, Caulfield LE, de Onis M, Ezzati M \& Rivera J (2008). Maternal and child undernutrition: global and regional exposures and health consequences. Lancet 371(9608):243-260. https://doi.org/10.1016/ S0140-6736(07)61690-0.

Eeng TA, Kwong CW, Yan LP, Mui NW \& Leong YS (2008). Knowledge, attitudes and sources of information on breastfeeding among pregnant mothers. Med \& Health, 3(31):30-37.

Fauzie R, Suradi R, Rejeki SS \& Hadinegoro S (2007). Pattern and influencing factors of breastfeeding of working mothers in several areas in Jakarta. Paediatr Indones 47(1):27-31.

Februhartanty J, Wibowo Y, Fahmida U \& Roshita A (2012). Profiles of eight working mothers who practiced exclusive breastfeeding in Depok, Indonesia. Breastfeeding Med 7(1):54-59. https://doi.org/10.1089/bfm.2011.0017.

Flacking R, Dykes F \& Ewald U (2010). The influence of fathers' socioeconomic status and paternity leave on breastfeeding duration: a population-based cohort study. Scand $J$ Public Health 38:337-343. https://doi. org/10.1177/1403494810362002.

Grassley JS \& Nelms TP (2008). Understanding maternal breastfeeding confidence: A Gadamerian hermeneutic analysis of women's stories. Health Care for Women Int 29(8-9):841-862. https://doi. org/10.1080/07399330802269527.

Guendelman S, Kosa JL, Pearl M, Graham S, Goodman J \& Kharrazi M (2009). Juggling work and breastfeeding: effects of maternity leave and occupational characteristics. Pediatrics 123(1):e38-e46. https://doi.org/10.1542/ peds.2008-2244.

Hirani SAA \& Karmaliani R (2013). Evidence based workplace interventions to promote breastfeeding practices among pakistaniworking mothers. Women Birth 26(1):10-16. https:// doi.org/10.1016/j.wombi.2011.12.005.

ILO (2010). Maternity at work - a review of national legislation. International Labour Organization, Geneva.

Kielmann K, Cataldo F \& Seeley J (2012). Introduction to Qualitative Research Methodology: A Training Manual. Department for International Development (DfID), United Kingdom. 
Kolinsky HM (2010). Respecting working mothers with infant children: the need for increased federal intervention to develop, protect, and support a breastfeeding culture in the united states. Duke J. Gend. Law Policy 17:333-362.

Kramer MS, Guo T, Platt RW, Sevkovskaya Z, Dzikovich I, Collet JP \& Bogdanovich N (2003). Infant growth and health outcomes associated with 3 compared with 6 mo of exclusive breastfeeding 1-3. Am J Clin Nutr 78:291-295.

Lawrence J \& Tar U (2013). The use of Grounded Theory Technique as a practical tool for qualitative data collection and analysis. The Electronic Journal of Business Research Methods 11(1):29-40.

Lestari A, Trisyani M \& Widiasih R (2014). Motivasi ibu bekerja dalam memberikan ASI Eksklusif di $P T$. Dewhirst Men's Wear Indonesia. Fakultas Ilmu Keperawatan Universitas Padjadjaran.

Manjilala (2012). The Experience of Breastfeeding Problems during The First Six Months Period After Delivery among Mothers Having Infants Aged 6-12 Months. Universitas Indonesia.

Marinelli KA, Moren K, Taylor \& The Academy of Breastfeeding JS (2013). Breastfeeding support for mothers in workplace employment or educational settings: summary statement. Breastfeed Med 8(1):137-142. https://doi. org/10.1089/bfm.2013.9999.

Marshall MN (1996). Sampling for qualitative research. Family Practice 13:522-525.

Ministry of Health (2008). PP Tentang Peningkatan Pemberian Air Susu Ibu Selama Waktu Kerja di Tempat Kerja. Ministr of Health, Jakarta.

Ministry of Health (2012). Peraturan Pemerintah Republik Indonesia Nomor 33 Tahun 2012 Tentang Pemberian Air Susu Ibu Eksklusif. Ministry of Health, Jakarta.

Nabulsi M (2011). Why are breastfeeding rates low in Lebanon? A qualitative study. BMC Pediatr 11(1):75. https://doi.org/10.1186/14712431-11-75.

Ong G, Yap M, Li FL, \& Choo TB. (2005). Impact of working status on breastfeeding in Singapore.

European Journal of Public Health 15:424-430. https://doi.org/10.1093/eurpub/cki030.

Rea MF (2004). Benefits of breastfeeding and women's health. J Pediatr (Rio J) 80(8):142146. https: / / doi.org/10.2223/1247.

Rempel LA \& Rempel JK (2011). The breastfeeding team: The role of involved fathers in the breastfeeding family. JHum Lact 27(2):115-121. https://doi.org/ 10.1177/0890334410390045.
Ryan AS, Zhou W \& Arensberg MB (2006). The effect of employment status on breastfeeding in the United States. Womens Health Issues 16(5): 243-251. https://doi.org/10.1016/j. whi.2006.08.001.

Shealy K, Li R, Benton-Davis S \& Grummer-Strawn LM (2005). The CDC Guide to Breastfeeding Interventions. U.S. Department of Health and Human Services, Centers for Disease Control and Prevention, Atlanta. https://doi. org/10.1097/00006223-200003000-00003.

Statistics Indonesia (2008). Statistics DKI Jakarta Provincial Office, Jakarta in Figures. Jakarta: BPS.

Statistics Indonesia (Badan Pusat Statistik - BPS), National Population and Family Planning Board (BKKBN), Ministry of Health \& ICF International (2013). Indonesia Demographic and Health Survey 2012. Jakarta, Indonesia: BPS, BKKBN, Kemenkes, and ICF International.

Tsai SY (2013). Impact of a breastfeeding-friendly workplace on an employed mother's intention to continue breastfeeding after returning to work. Breastfeeding Medicine 8(2):210-216. doi: 10.1089/bfm.2012.0119.

UNICEF (2011). Programming Guide Infant and Young Child Feeding. Nutrition Section, UNICEF, (May), 173. https://www.unicef.org/nutrition/ files/Final_IYCF_programming_guide_2011. pdf

Weber D, Janson A, Nolan M, Wen LM \& Rissel C (2011). Female employees' perceptions of organisational support for breastfeeding at work: findings from an Australian health service workplace. Int Breastfeed $J$ 6(1):19. https://doi.org/10.1186/1746-4358-6-19.

Wen LM, Baur LA, Rissel C, Alperstein G \& Simpson JM (2009). Intention to breastfeed and awareness of health recommendations: findings from first-time mothers in southwest Sydney, Australia. Int Breastfeed $J$ 4(9):1-8. https://doi.org/10.1186/1746-4358-4-9.

Wilson DR, Cooper C, Plunk K \& Severson M (2012). Overcoming breastfeeding challenges: A qualitative inquiry. Clinical Lactation 3(4):155$160(6)$.

Yeasmin S \& Rahman KF (2012). 'Triangulation' research method as the tool of social science research. Bup Journal 1(1):154-163.

Zafar SN \& Bustamante-Gavino MI (2008). Breastfeeding and working full time: Experiences of nurse mothers in karachi, Pakistan. International Journal of Caring Science 1(3): 132-139. 